Full length article

\title{
Combining gradient structure and TRIP effect to produce austenite stainless steel with high strength and ductility
}

\author{
X.L. Wu ${ }^{\text {a, }}{ }^{*}$, M.X. Yang ${ }^{\text {a }}$, F.P. Yuan ${ }^{\text {a }}$, L. Chen ${ }^{\text {a }}$, Y.T. Zhu ${ }^{\text {b, c }}$ \\ a State Key Laboratory of Nonlinear Mechanics, Institute of Mechanics, Chinese Academy of Sciences, Beijing 100190, China \\ ${ }^{\mathrm{b}}$ Department of Materials Science and Engineering, North Carolina State University, Raleigh, NC 27695, USA \\ ${ }^{c}$ Nano Structural Materials Center, School of Materials Science and Engineering, Nanjing University of Science and Technology, Nanjing, Jiangsu 210094, \\ China
}

\section{A R T I C L E I N F O}

\section{Article history:}

Received 17 March 2016

Received in revised form 20 April 2016

Accepted 20 April 2016

Available online 28 April 2016

\section{Keywords:}

Gradient structure

Strain hardening

Ductility

Transformation-induced plasticity

Strain partitioning

\begin{abstract}
A B S T R A C T
We report a design strategy to combine the benefits from both gradient structure and transformationinduced plasticity (TRIP). The resultant TRIP-gradient steel takes advantage of both mechanisms, allowing strain hardening to last to a larger plastic strain. 304 stainless steel sheets were treated by surface mechanical attrition to synthesize gradient structure with a central coarse-grained layer sandwiched between two grain-size gradient layers. The gradient layer is composed of submicron-sized parallelepiped austenite domains separated by intersecting $\varepsilon$-martensite plates, with increasing domain size along the depth. Significant microhardness heterogeneity exists not only macroscopically between the soft coarse-grained core and the hard gradient layers, but also microscopically between the austenite domain and $\varepsilon$-martensite walls. During tensile testing, the gradient structure causes strain partitioning, which evolves with applied strain, and lasts to large strains. The $\gamma \rightarrow \alpha^{\prime}$ martensitic transformation is triggered successively with an increase of the applied strain and flow stress. Importantly, the gradient structure prolongs the TRIP effect to large plastic strains. As a result, the gradient structure in the 304 stainless steel provides a new route towards a good combination of high strength and ductility, via the co-operation of both the dynamic strain partitioning and TRIP effect.
\end{abstract}

(c) 2016 Acta Materialia Inc. Published by Elsevier Ltd. All rights reserved.

\section{Introduction}

It has been a challenge to produce metals and alloys with both high strength and high ductility [1-5]. High strength can be achieved by well-known strategies such as grain refinement, deformation twinning, nano-twins, second-phase particle strengthening, solution hardening, and work hardening. However, this usually comes with sacrifice of ductility [4-9]. Ductility is measured under tensile loading either as total elongation to failure or as uniform elongation. The decrease in ductility with increasing strength is often observed because i) high strength metals often have low strain hardening rate, as in the case of cold worked metals and nanostructured metals [1,3-7]; ii) according to the Considère criterion, a high-strength metal would need a higher strain hardening rate to reach the same uniform elongation as that of a lowstrength metal $[8,10]$.

\footnotetext{
* Corresponding author.

E-mail address: xlwu@imech.ac.cn (X.L. Wu).
}

A promising strategy for simultaneously improving the strength and ductility is proposed recently by combining several plastic deformation and strain hardening mechanisms in steels [11-15]. Each hardening mechanism may be active over a certain strain range, but several of them together could collectively produce a high strain-hardening rate to improve ductility, when at least one of them persists over a wide range of the imposed tensile strains $[11,12]$. One of the most effective approaches to increase both strain hardening and ductility is the transformation-induced plasticity, i.e. the TRIP effect, which is observed in dual-/multi-phase steels [11-13,16-18], TRIP steels [11,12,19-23], bainite steels [15,24], etc. In these steels, the phase-specific deformation mechanism takes effect at different stress or strain levels and therefore, the global plastic response is composite-like, which critically depends on the evolution of stress transfer and dynamic strain partitioning among different phases [11,12]. In addition, martensitic transformation is activated at varying local stress or strain levels during the tensile tests, which provides not only higher strain hardening but also excellent plasticity, when the TRIP effect is designed to sustain over a wide strain range [11,12]. In addition, to produce good TRIP effect, 
the phase transformation needs to persist up to large strains. High strain hardening rate is reported to originate from the harder phase produced by phase transformation as well as mechanical incompatibility, i.e. strain partitioning, between different phases with different flow stresses [11-13,16]. Strain partitioning causes strain gradient at phase boundaries, which is accommodated by geometrically necessary dislocations $[25,26]$ and consequently enhances strain hardening [27]. Recently, a microstructural design concept, referred to the TRIP-maraging steel, is proposed [11]. The strength and ductility were improved simultaneously from three effects, i.e. the TRIP effect by nano-scale austenite, maraging effect by nano-precipitation, and composite effect due to strain partitioning.

Recently, another approach employing gradient structure (GS) has been reported to produce a superior combination of yield strength and ductility [28-34]. The GS often consists of the grainsize gradient layers (GLs) with increasing grain sizes along the depth towards the central coarse-grained (CG) core layer. For gradient structured metals with stable gradient structures, high ductility is attributed to an extra strain hardening due to the presence of strain gradient and the change of stress states, which generates geometrically necessary dislocations and promotes the generation and interaction of forest dislocations [29]. The GS may produce an intrinsic synergetic strengthening, with its yield strength much higher than the sum of separate gradient layers [34]. This is due to the macroscopic strength gradient and mechanical incompatibility between layers [29-34]. Such a mechanical incompatibility was also found to produce high back stress, which may contribute to both strength and ductility $[3,35]$.

The objective of this investigation is to propose a design strategy, referred to as the TRIP-gradient steel, to produce high strength and high ductility. The 304 austenite stainless steel (304ss) is chosen as the model material due to its TRIP effect during tensile testing [36-44]. The mechanical properties of 304ss have been extensively studied [45-48]. In early studies, gradient structure in 304ss was reported to produce a high yield strength of $950 \mathrm{MPa}$ with a ductility of $30 \%[49,50]$, but its plastic deformation and strain hardening mechanisms were not explored. In this work, we combined the gradient structure with the TRIP effect in 304ss. In particular, the TRIP effect was designed to operate in a wider strain range, which depends on dynamic strain partitioning associated with the composite-like deformation in the GS. Microstructural observations and measurements were performed on tensile deformed samples to correlate the excellent strength and ductility to the strain partitioning and TRIP effect.

\section{Experimental procedure}

\subsection{Materials and SMAT process}

In the present investigation, as-annealed AISI 304ss disks were used, with a diameter of $100 \mathrm{~mm}$ and thickness of $0.5,1$ and $2 \mathrm{~mm}$, respectively. The chemical composition was $0.04 \mathrm{C}, 0.49 \mathrm{Si}, 1.65 \mathrm{Mn}$, $7.8 \mathrm{Ni}, 16.8 \mathrm{Cr}, 0.37 \mathrm{Mo}$ and the balance Fe (all in mass\%).

The surface mechanical attrition treatment (SMAT) technique was used to produce the gradient structured 304ss specimens, with a central CG layer sandwiched between two gradient layers (GLs). During the SMAT process, spherical steel shots of 3-mm in diameter were accelerated to high speeds using high-power ultra-sound to impact on the sample disk [51,52]. Because of the high frequency of the system $(20 \mathrm{kHz})$, the entire surface of the component is peened with high density of impacts over a short period of time. The SMAT processing time was the same for both sides of each disk, which was 1-15 min. No crack was observed on the sample surface after SMAT processing.

\subsection{Mechanical property tests}

Tensile specimens were cut from the SMAT-processed disks. They are dog-bone shaped with a gauge length of $15 \mathrm{~mm}$ and width of $3 \mathrm{~mm}$. Specimens of varying thicknesses in the gradient layers were also prepared for both tensile testing and X-ray diffraction (XRD) measuements of phase transitions at different depths and applied tensile strains. These specimens were prepared by polishing away the whole SMAT-processed sample from one side via mechanical polishing at first and later electro-polishing of at least $150 \mu \mathrm{m}$ thick at room temperature, leaving behind the specimen of desired thickness.

Uniaxial tensile tests were carried out at a strain rate of $5 \times 10^{-4} \mathrm{~s}^{-1}$ at room temperature using an MTS Landmark testing machine. An extensometer was used to measure the strain during tensile testing. Uniaxial tensile stress-relaxation tests were also performed under strain-control mode at room temperature. Upon reaching a designated relaxation strain, the strain was maintained constant while the stress was recorded as a function of time. After the first relaxation over an interval of $60 \mathrm{~s}$, the specimen was reloaded by a strain increment of $0.6 \%$ at a strain rate of $5 \times 10^{-4} \mathrm{~s}^{-1}$ for next relaxation. Three stress relaxations were conducted for each designated strain. All tensile tests were performed three times on average for each condition to verify the reproducibility of the monotonic and cyclic tensile stress-strain curves.

Vickers microhardness (Hv) indentations were made in the gauge section to measure the Hv evolution, prior to and after tensile testing respectively, under a $25 \mathrm{~g}$ load across the cross-section of the gradient structured specimen.

\subsection{Microstructural characterization}

Transmission electron microscopy (TEM) observations were conducted to investigate microstructural evolution in the GS samples during tensile tests in a JEM 2010 microscope with an operating voltage of $200 \mathrm{kV}$. TEM disks were cut from the gauge section of tensile samples after suspension of tensile testing at designated strains.

Electron back-scattered diffraction (EBSD) observations were conducted using a high-resolution field emission Cambridge S-360 SEM equipped with a fully automatic Oxford Instruments Aztec 2.0 EBSD system (Channel 5 Software). A scanning step of 0.03-0.08 $\mu \mathrm{m}$ was performed during the EBSD acquisition. Due to spatial resolution of the EBSD system, the collected Kikuchi patterns can be obtained automatically at a step resolution of $0.02 \mu \mathrm{m}$ and correspondingly misorientations less than $2^{\circ}$ cannot be identified. The samples for EBSD examinations were mechanically polished carefully followed by electro-polishing using an electrolyte of $90 \mathrm{vol} \%$ acetic acid and $10 \mathrm{vol} \%$ perchloric acid with a voltage of $40-45 \mathrm{~V}$ at about $-40{ }^{\circ} \mathrm{C}$ in a Struers LectroPol-5 facility.

$\mathrm{X}$-ray diffraction (XRD) measuements were performed to obtain the phase transfor- mation information during tensile tests using a Philips Xpert X-ray diffractometer with $\mathrm{Cu} \mathrm{K} \alpha$ radiation. The samples were carefully prepared by mechanical polishing plus electropolishing from the surface to reach the designated depths after suspending tensile testing at varying designated strains. The phase volume fraction was estimated from the peak integrated intensities $\mathrm{I}_{\mathrm{hkl}}$ after background subtraction. The volume fraction of $\alpha^{\prime}$ martensite, $V_{\alpha^{\prime}}$, was calculated using the equation, $\mathrm{V}_{\alpha^{\prime}}=\mathrm{I}_{\mathrm{bcc}(110)} / \mathrm{I}_{\mathrm{bcc}(110)}+\mathrm{I}_{\mathrm{fcc}(111)}$. 


\section{Results}

\subsection{Mechanical behaviors}

\subsubsection{Tensile property and strain hardening}

Fig. 1 shows the tensile behaviors in various gradient structured specimens as well as the CG specimens for comparison. Fig. 1(a) displays the quasi-static engineering stress-strain curves. A twostage flow behavior is visible in the stress-strain $(\sigma-\varepsilon)$ curves of both the GS and CG samples. Taking CG as an example, the $\sigma-\varepsilon$ curve consists of a parabolic segment at the initial stage, followed by a sigmoidal or S-shape segment at the second stage. This leads to two inflection points on the strain hardening rate $\left(\Theta=\frac{\partial \sigma}{\partial \varepsilon}\right)$ versus true strain curve as shown in Fig. 1(d). Two inflection points are marked by $I_{1}$ and $I_{2}$, respectively, corresponding to the onset of $\Theta$ up-turn and down-turn. The initial deformation stage is characterized by a low flow stress and a decreasing strain hardening rate with strain. This stage is associated with planar slip of partial and dissociated dislocations and the formation of $\varepsilon$-martensite plates $[38,39]$. The second stage begins with a rapid rise in $\Theta$, i.e. $\Theta$ rise, due to the deformation-induced $\gamma \rightarrow \alpha^{\prime}$-martensite transformation [41-48], which is one of the major contributors to the TRIP effect. The final drop in $\Theta$ is caused by dynamic recovery.

Fig. 1(a) shows the increase of yield strength $\left(\sigma_{0.2}\right)$ of all gradient-structured specimens of 1-mm thick (superscript represents specimen thickness in $\mathrm{mm}$ ) with increasing SMAT duration (subscript, minutes), with a slight decrease of uniform tensile elongation $\varepsilon_{u}$. For example, the processing by SMAT for $15 \mathrm{~min}$, i.e. $\mathrm{GS}_{15}^{1}$, increased $\sigma_{0.2}$ by $132 \%$ while $\varepsilon_{u}$ dropped by only $30 \%$, which is consistent with an early report on gradient structured IF steel [29]. Interestingly, the combination of $\sigma_{0.2}$ and $\varepsilon_{u}$ may be optimized by adjusting either the SMAT processing period or sample thickness [34]. Taking the $\mathrm{GS}_{15}^{2}$ sample (2-mm thick) as an example, which is twice thick as the GS ${ }_{15}^{1}$, both its $\sigma_{0.2}$ and $\varepsilon_{\mathrm{u}}$ increased over those of
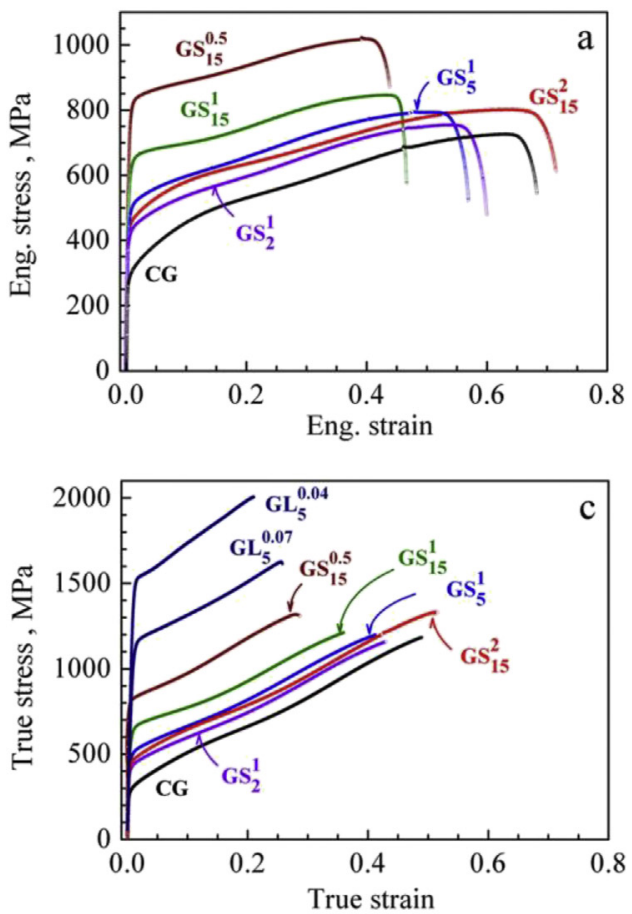

the CG sample. As the original thickness was reduced from 1 to $0.5 \mathrm{~mm}, \sigma_{0.2}$ increased significantly, but uniform tensile elongation also decreased.

Stand-alone gradient layers of various thicknesses from $\mathrm{GS}_{5}^{1}$ were tested further to investigate their mechanical behaviors. The $\sigma-\varepsilon$ curves are shown in Fig. 1(b). The top layer of $20 \mu \mathrm{m}$ thick, i.e. $\mathrm{GL}_{5}^{0.02}$ film, has $\sigma_{0.2}$ as high as $1700 \mathrm{MPa}$ but necking occurred soon after yielding. Increasing the thickness to 40 and $70 \mu \mathrm{m}\left(\mathrm{GL}_{5}^{0.04}\right.$ and $\mathrm{GL}_{5}^{0.07}$ films) led to typical two-stage flow behavior similar to that in $\mathrm{GS}_{5}^{1}$, but with uniform elongation even above $20 \%$.

Fig. 1(c) shows the true stress-strain curves of all GS samples and GL films, which show high strain hardening during the uniform deformation. The flow stress reached as high as $2 \mathrm{GPa}$ in $\mathrm{GL}_{5}^{0.04}$. Fig. 1(d) shows global strain hardening responses of all GS samples. For the CG sample, $\Theta$ decreases first, which is followed by a large increase, and then, drops again all the way to final necking. All GS samples show a similar trend of $\Theta$ evolutions. The only difference is the shifting of $\Theta$ rise to low starting stain. For example, the strain is 0.1 for $\Theta$ rise in $G_{15}^{1}$, which is much less than 0.2 for CG. It is noteworthy, however, that the $\Theta$ rise in the GL films, e.g. $\mathrm{GL}_{5}^{0.04}$, begins at a very small strain as compared to that in GS samples.

\subsubsection{Microhardness evolution}

The microhardness (Hv) evolution may reveal strain hardening behaviors locally in the GS samples during tensile deformation. Based on the $\Theta-\varepsilon$ curve of $\mathrm{GS}_{5}^{1}$ sample shown in Fig. 1(d), several tensile strains were selected for conducting Hv measurements to correlate the global strain hardening with local strain hardening.

Fig. 2(a) shows the Hv profile at varying applied global tensile strains in $\mathrm{GS}_{5}^{1}$. Before tensile testing, Hv gradient appeared along the depth, clearly demarcating the central CG core and GL of $\sim 250 \mu \mathrm{m}$ deep on both sides. The Hv value near the treated surface is $3.5 \mathrm{GPa}$, much larger than $2 \mathrm{GPa}$ in the central CG core. At the tensile strains of 0.05 and 0.1 prior to the onset of $\Theta$ rise (Fig. 1(d)),
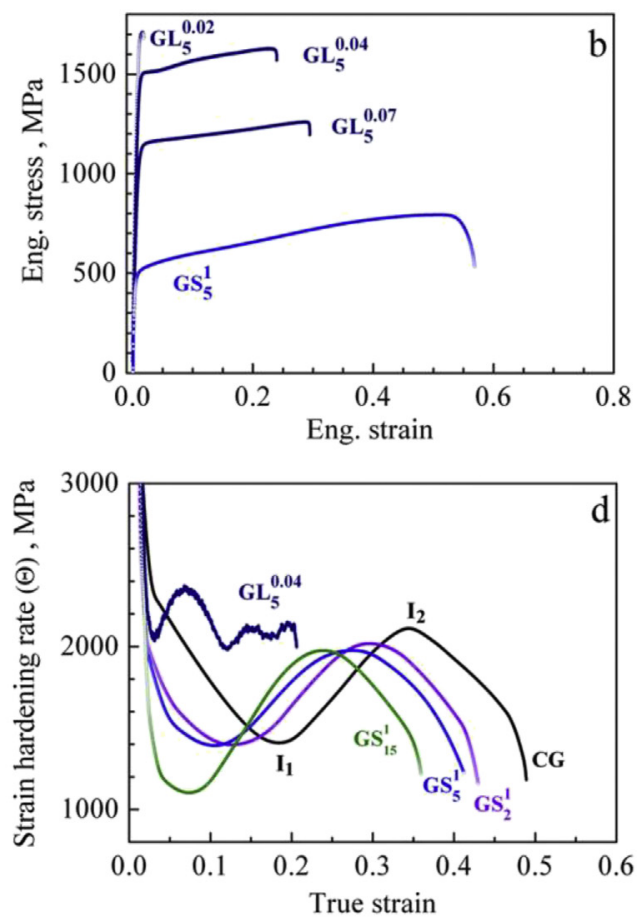

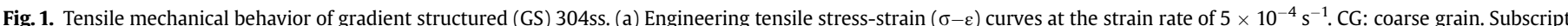

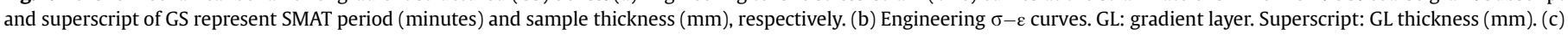
True $\sigma-\varepsilon$ curves. (d) Strain hardening rate $(\Theta)$ versus true strain curves. $\mathrm{I}_{1}$ and $\mathrm{I}_{2}$ on the $\sigma-\varepsilon$ curve of CG: inflection points. Note that the strain is applied global strain. 

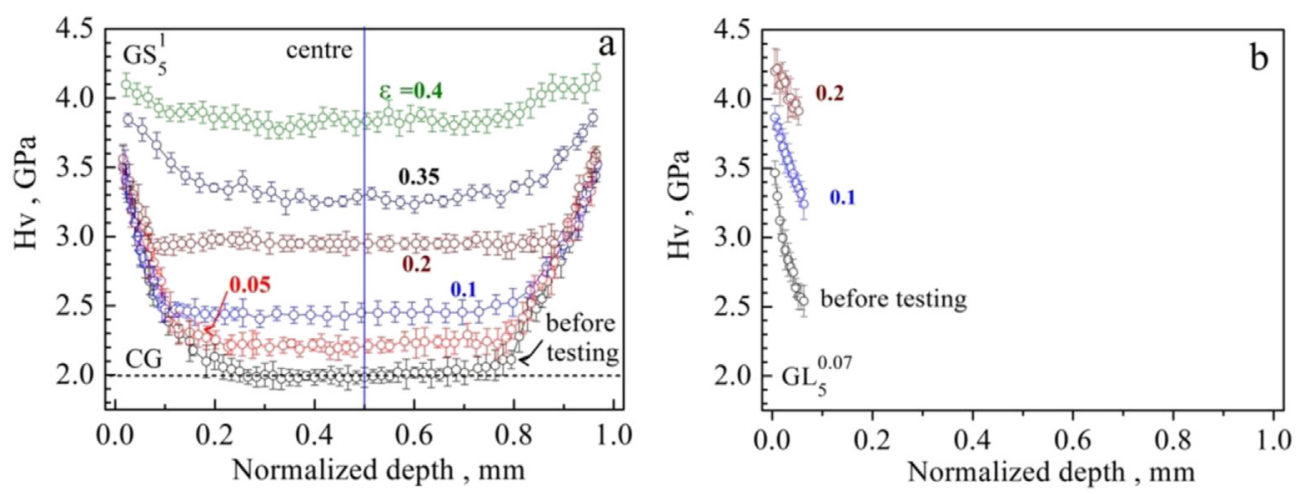

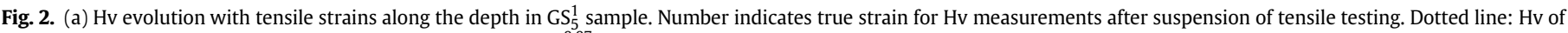
as-annealed CG sample. (b) Hv evolution along the depth in $\mathrm{GL}_{5}^{0.07}$ sample. Note that the strain is applied global strain.

Hv increased uniformly in the central CG layer, but hardly changed in most of the gradient layer. Even when the applied global tensile strain increased to 0.22 , and the $\Theta$ rise has already started (Fig. 1(d)), the $\mathrm{Hv}$ in the top surface hardly changed at all, in contrast to the significant Hv increase in the CG layer. An obvious Hv rise in the top surface is not observed until tensile strain reached 0.35 . Note that this strain is far beyond the $\Theta$ peak and already in the strain range of final $\Theta$ drop. Finally, by the end of uniform elongation at the strain of 0.4 , the top layer showed an even higher $\mathrm{Hv}$ increase while the initial Hv gradient almost disappeared, which is very different from the reported Hv evolution in IF steel [29]. The $\mathrm{Hv}$ evolution was also measured in the free-standing $\mathrm{GL}_{5}^{0.07}$ film during tensile deformation as shown in Fig. 2(b). Hv rises instantly even at true strain of 0.1 , in sharp contrast to what is observed in $\mathrm{GS}_{5}^{1}$ where Hv remains unchanged as shown in Fig. 2(a).

\subsubsection{Dislocation density evolution}

Fig. 1(d) reveals a $\Theta$ drop soon after yielding in GS samples much faster than that in CG. The stress relaxation tests were then conducted to correlate the $\Theta$ drop with the mobile dislocation behavior during this initial strain stage. Fig. 3(a) shows the $\sigma-\varepsilon$ curve in both $\mathrm{GS}_{5}^{1}$ and CG samples by stress relaxation testing. A number of relaxation strains were selected to cover the initial strain stage. Fig. 3(b) shows the decay curves of the mobile dislocation density, $\rho_{\mathrm{m}}$, with time at varying relaxation strains. The details for calculating $\rho_{\mathrm{m}}$ can be found elsewhere [29,53]. $\rho_{\mathrm{m}}$ is featured by an initial rapid drop followed by leveling-off as relaxation time extends. The final mobile dislocation density, $\rho_{\text {equi, }}$ is shown in Fig. 3(c) as a function of relaxation strains.

Interestingly, $\rho_{\text {equi }}$ dropped initially in $\mathrm{GS}_{5}^{1}$ sample until a strain of 0.03 and then increased until a strain of $\sim 0.1$, followed by a final drop. In contrast, the $\rho_{\text {equi }}$ in the CG sample rose first up to a strain of 0.04 and then dropped continuously. The rise in $\rho_{\text {equi, }}$ which relates to the total dislocation density, is usually related to the increase in strain hardening [29,53]. Comparing Figs. 1(d) and 3(c) reveals that the increase in $\rho_{\text {equi }}$ coincides with the initial drop of $\Theta$ up to the strain of 0.1 . Hence, even with a rapid $\Theta$ drop, the uniform deformation may still continue mainly due to the accumulation of dislocations. This is well in line with the observation in the gradient structured IF steel [29].

\subsection{Microstructural evolution}

We studied both the microstructure and the $\gamma \rightarrow \alpha^{\prime}$-martensitic transformation before and after tensile testing in $\mathrm{GS}_{5}^{1}$ samples to correlate the tensile property and strain hardening with the microstructural evolution.

\subsubsection{Microstructure by SMAT processing}

Fig. 4 shows EBSD images in $\mathrm{GS}_{5}^{1}$ sample after SMAT processing. Fig. 4(a) shows equi-axial grains of austenite with an average grain size of $25 \mu \mathrm{m}$ in the central CG layer. Fig. 4(a-1) is an overlay of the corresponding EBSD image map (in grayscale) and the martensite phase map (in green), which indicates the presence of $\alpha^{\prime}$ martensite with a volume fraction of $\sim 6 \%$ in original austenite of CG samples. The phases become indiscernible in the gradient layer mainly due to the small microstructural sizes in the severely deformed state. As seen in Fig. 4(b)/(b-1) and 4(c)/(c-1), the high density of band-like stripes are visible in most grains. This indicates significant refinement of original coarse grains by these stripes, even though the contours of most of original grain boundaries are still visible.
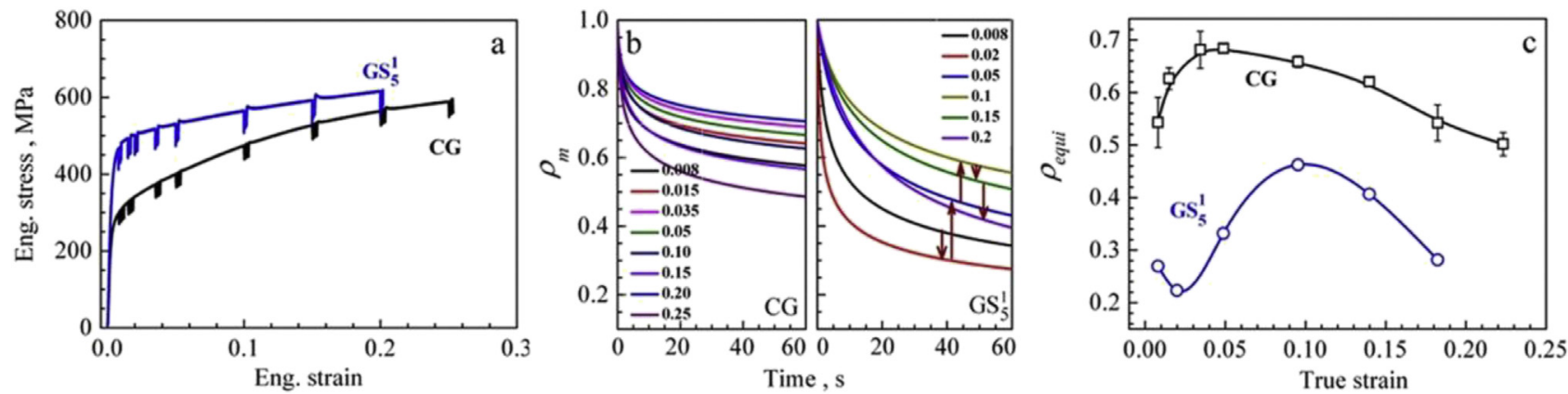

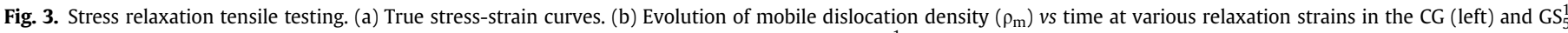
sample (right). Arrows in right figure indicate $\rho_{\text {equi }}$ change with strains. (c) $\rho_{\text {equi }}$ vs true strain in $\mathrm{GS}_{5}^{1}$ and CG samples. Note that the strain is applied global strain. 

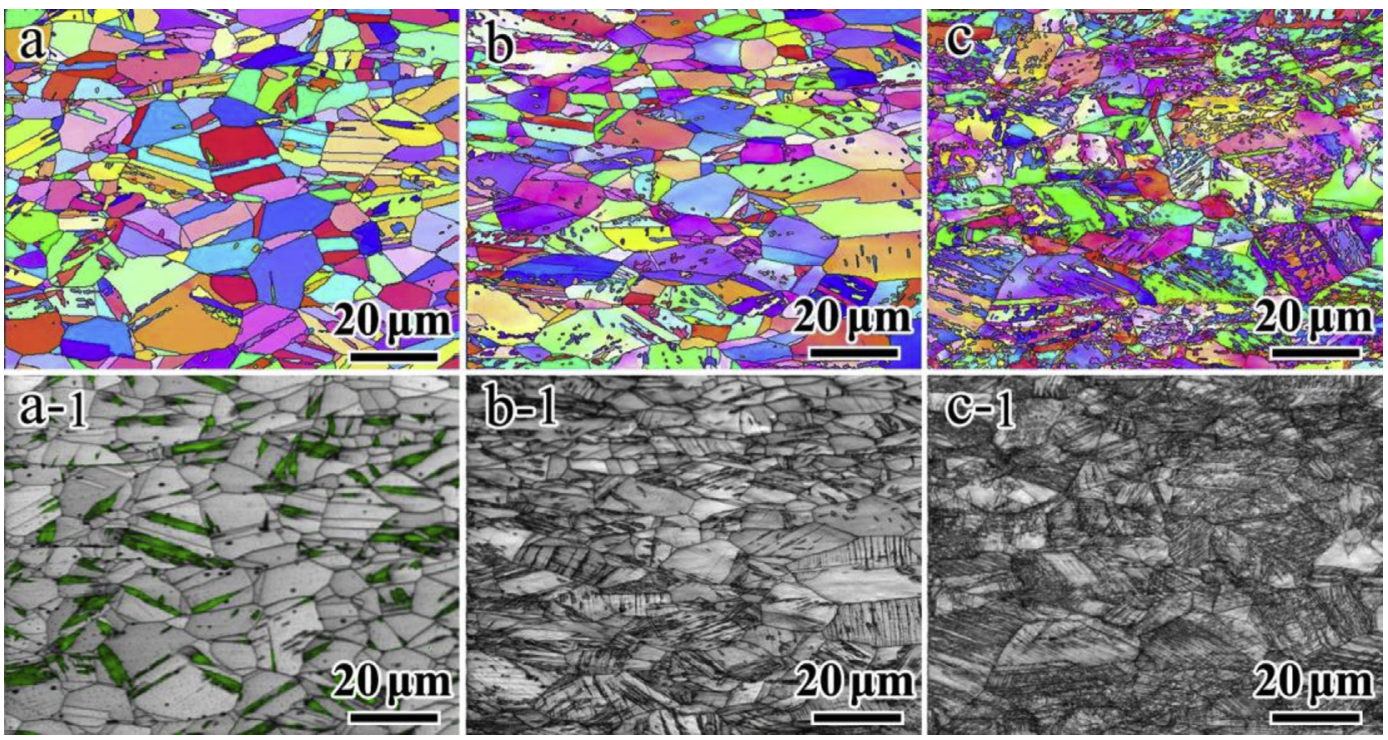

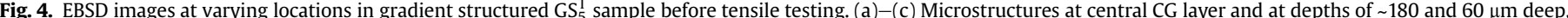

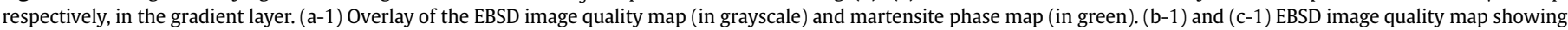
deformation fringes. (For interpretation of the references to colour in this figure caption, the reader is referred to the web version of this article.)

Detailed TEM observations were then conducted to investigate the microstructure and constituent phases in the gradient layer of $\mathrm{GS}_{5}^{1}$ sample. Fig. 5 is a series of TEM images showing typical microstructure in the original coarse-grain interior at the depth of $\sim 180 \mu \mathrm{m}$. Fig. 5(a) shows the intersecting bands of two $\{111\}_{\gamma}$ orientations which are originated from grain boundaries and extend into the grain interior. The initial constituent phase in these bands is $\varepsilon$-martensite, which was formed at low strains by the planar slip of partial dislocations due to low stacking fault energy of 304ss $[37,38]$. These $\varepsilon$-martensite bands subdivide the original coarse grains into a large number of submicron-sized parallelepiped domains with austenite interior [37,38,44,50]. Fig. 5(b) and (c) are enlarged bright- and dark-field images and its corresponding selected area electron diffraction (SAED) pattern is given in Fig. 5(f).
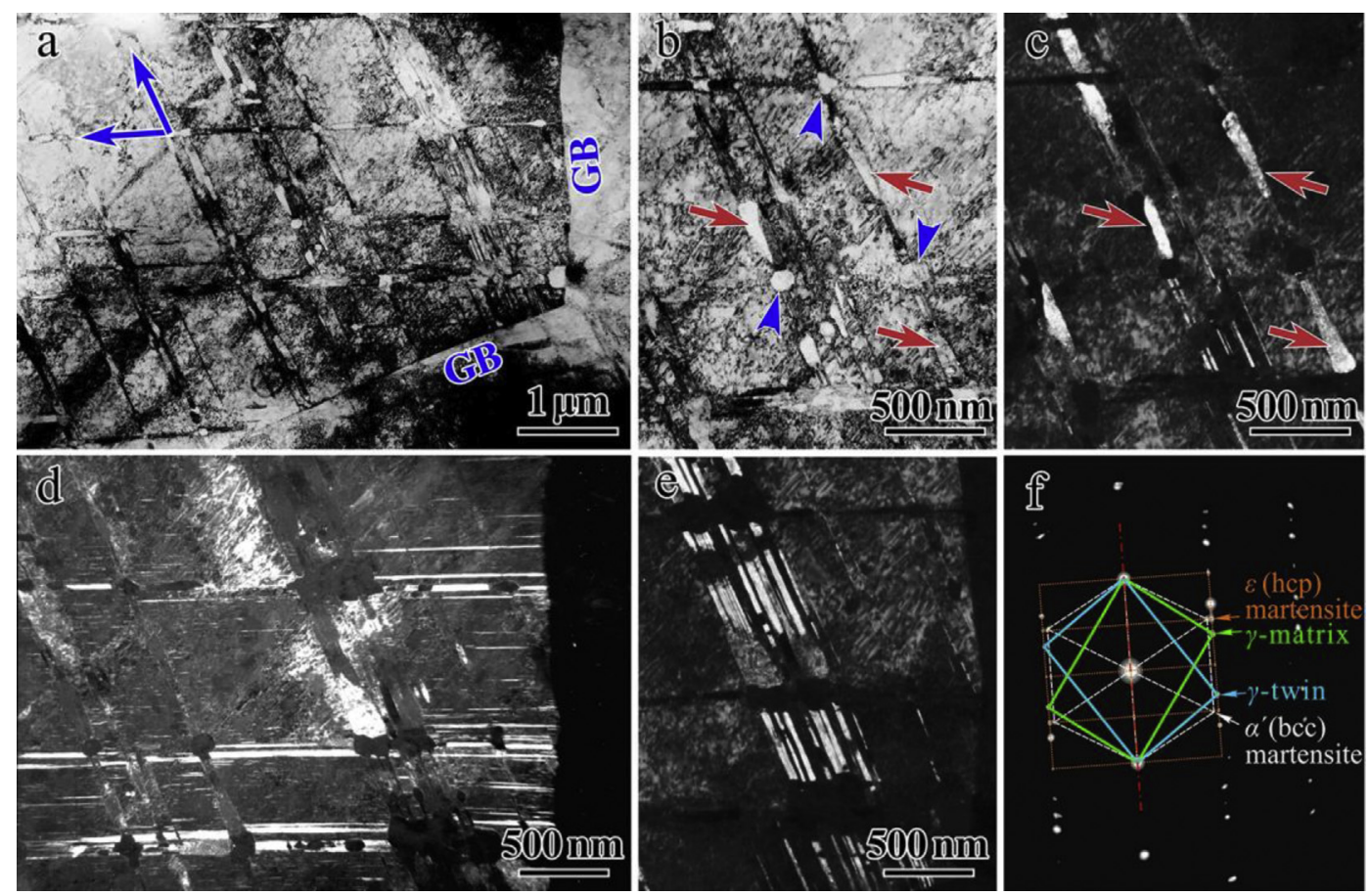

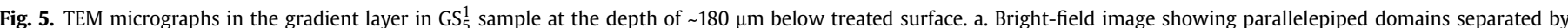

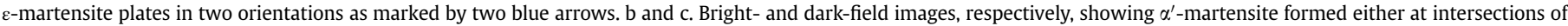

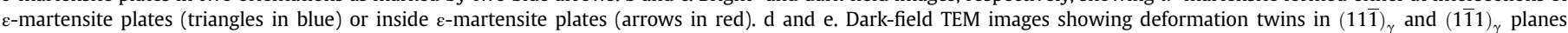

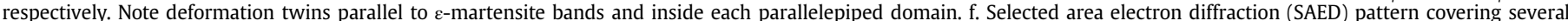

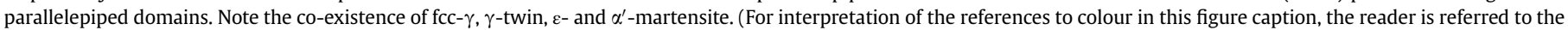
web version of this article.) 
Two types of $\alpha^{\prime}$-martensite are observed in the shear bands. One is granular, as indicated by blue triangles, which is nucleated at the intersections of $\varepsilon$-martensite bands [37,44]. The other is plateshaped, which is located inside and along $\varepsilon$-martensite bands, as indicated by red arrows shown in Fig. 5(b) and (c). Both were formed via the $\varepsilon \rightarrow \alpha^{\prime}$-martensite transformation [42-44]. Moreover, deformation twins of two different orientations, parallel to $\varepsilon$-martensite bands, are revealed by dark-field TEM observations, as shown in Fig. 5(d) and (e). These twins are close to $\varepsilon$-martensite bands, but their growth is blocked by $\varepsilon$-martensite bands.

The parallelepiped domain is typical of the microstructural units in the gradient layer during SMAT processing. Fig. 6(a) and (b) show the presence of the submicron-sized domains by subdivision of $\varepsilon$-martensite bands at the depth of $\sim 100$ and $50 \mu \mathrm{m}$, respectively. Parallel domain walls are clearly seen in Fig. 6(b), oriented along two $\langle 110\rangle$ zone axes so that these two domain walls are edge on. The third domain wall can be seen in Fig. 6(a) because it is not edge on. As shown in Fig. 6(b), the domains are elongated with one side much longer than the other. Fig. 7 shows that the sizes of both domain sides decrease when approaching the treated surface in the gradient layer.

Shear bands are occasionally observed in the gradient layers. The SMAT may produce a strain rate as high as $10^{3} \mathrm{~s}^{-1}$ near the treated surface [51]. Two types of microstructures are observed in shear bands. One, as shown in Fig. 8(a), consists of $\varepsilon$-martensite bands with a high density of stacking faults, with the formation of granular $\alpha^{\prime}$-martensite by the $\varepsilon \rightarrow \alpha^{\prime}$ transformation. The other, as shown in Fig. 8(b), consists of ultrafine-grained austenite, which is
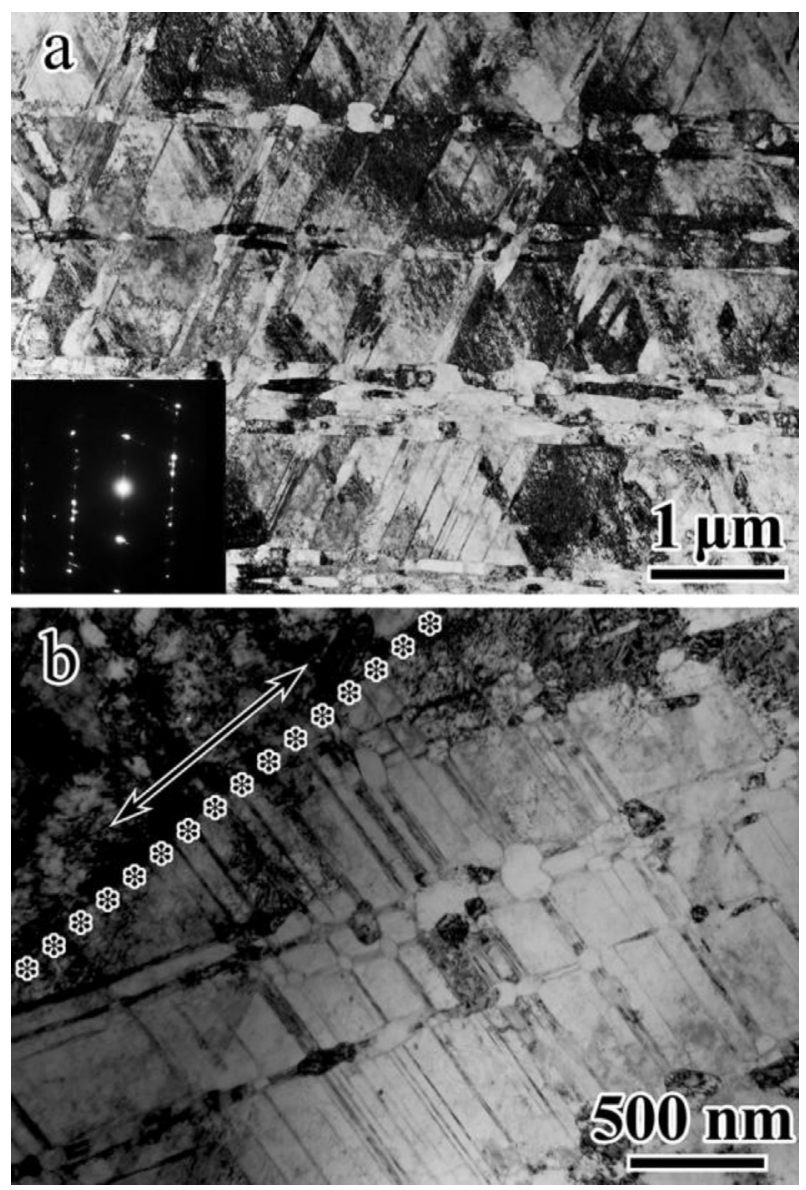

Fig. 6. TEM micrographs showing parallelepiped austenite domains separated by $\varepsilon$-martensite bands in the gradient layer at the depth of (a) $\sim 100 \mu \mathrm{m}$ and (b) $50 \mu \mathrm{m}$.

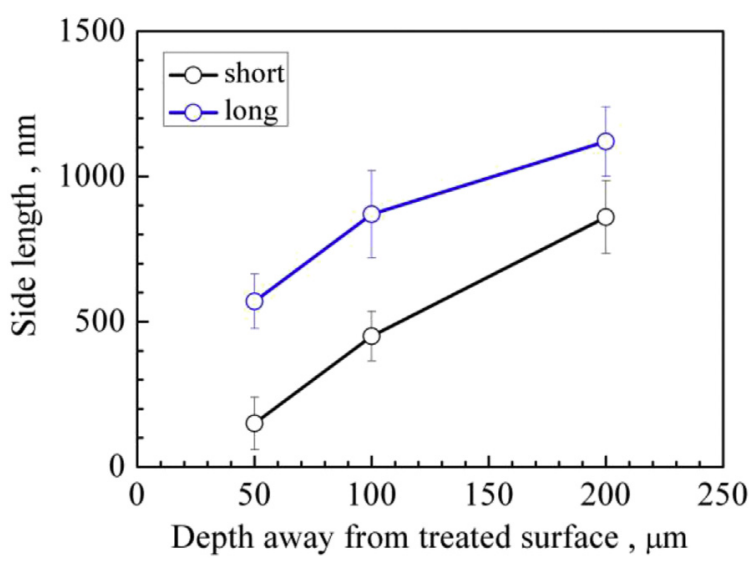

Fig. 7. Statistic side lengths of parallelepiped domains along the depth.
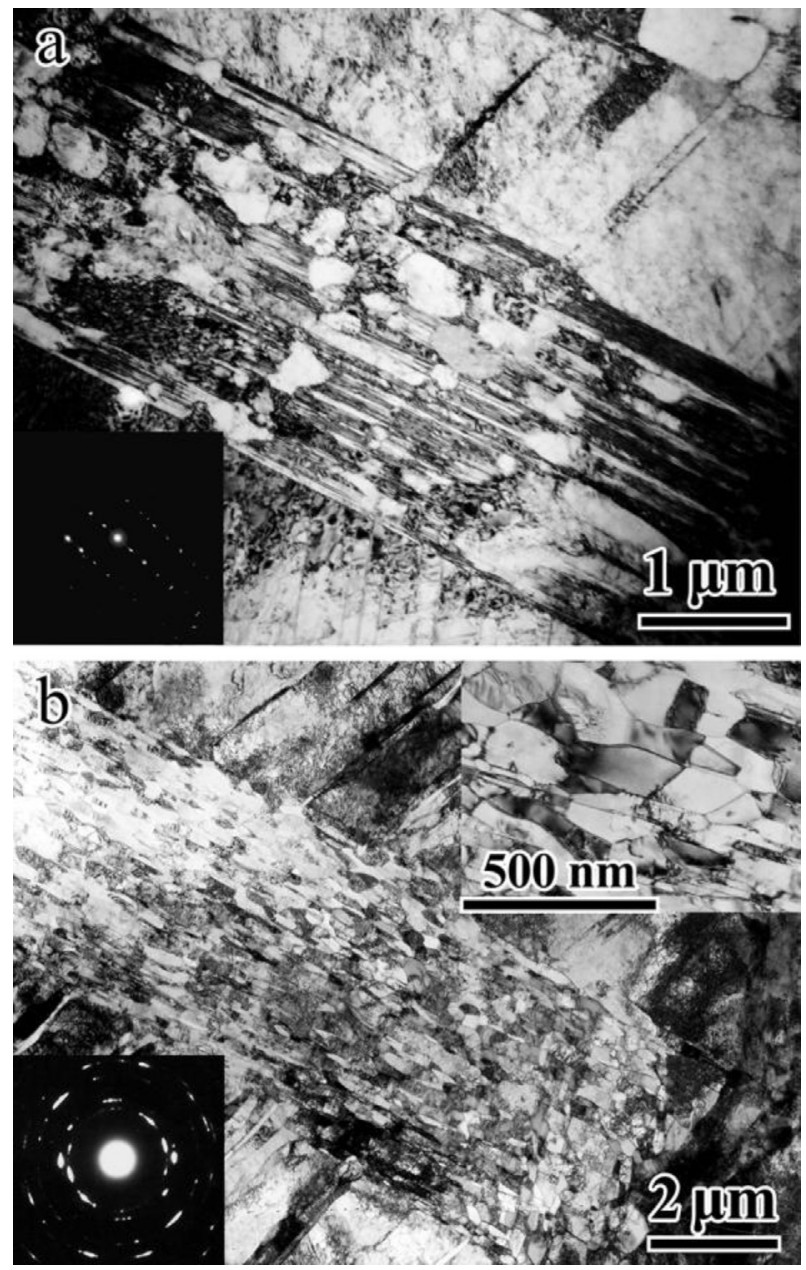

Fig. 8. TEM micrographs showing two types of shear bands in gradient layer. (a) Stacking faults in a shear band that contains granular $\alpha^{\prime}$-martensite at $\sim 80 \mu \mathrm{m}$ deep from treated surface. Lower left inset shows the SAED pattern indicating the $\varepsilon$-martensite with a $[\overline{1} 100]$ zone axis. (b) Recrystallized austenite grains in a shear band. The upper right inset is an enlarged image of dislocation-free austenite grains in the shear band and the lower left inset is an SAED pattern showing low-angle misorientations between the austenite grains.

likely formed by the $\alpha^{\prime} \rightarrow \gamma$ reverse transformation due to heat effect in the shear bands [54-56]. The upper-right inset is an enlarged image showing dislocation-free, recrystallized austenite 
grains. The bottom-left inset is an SAED pattern, indicating low angle grain boundaries of these austenite grains.

\subsubsection{Change of $\alpha^{\prime}$-martensite fraction during tensile testing}

The $\gamma \rightarrow \alpha^{\prime}$-martensitic transformation is expected to be affected by both the austenite domain size in the gradient layer and the local applied strains and stresses during the tensile test. The domain size gradient observed in the gradient layer is expected to affect the $\gamma \rightarrow \alpha^{\prime}$-martensitic transformation and consequently the TRIP effect during the tensile testing. A series of XRD measurements was carried out to measure $V_{\alpha^{\prime}}$ at varying depths and tensile strains during tensile testing of $\mathrm{GS}_{5}^{1}$ sample. The strains were chosen based on the $\Theta-\varepsilon$ curve in Fig. 1(d) and Hv change in Fig. 2. The objective is to correlate $\mathrm{V}_{\alpha^{\prime}}$ with the global and local strain hardening and to clarify the effect of gradient structure on TRIP effect.

Fig. 9(a) shows several typical XRD spectra at varying depths and applied strains in the $G S_{5}^{1}$ sample. Fig. 9(b) plots the calculated $\mathrm{V}_{\alpha^{\prime}}$ as a function of applied tensile strain at varying depths. The results clearly indicate the dependence of $V_{\alpha^{\prime}}$ on both depths and global tensile strains. For the central CG core, $V_{\alpha^{\prime}}$ remains around $5 \%$ at low strains. It does not rise rapidly until the strain of 0.1 and lasts up to 0.22 . Finally, $\mathrm{V}_{\alpha^{\prime}}$ levels off at the strain of 0.25 and keeps unchanged until the end of the uniform deformation. It is noted that the strain range for the rapid rise of $V_{\alpha^{\prime}}$ coincide with the rise of the global $\Theta$ as shown in Fig. 1(d). The level-off of $V_{\alpha^{\prime}}$ indicates the absence of $\gamma \rightarrow \alpha^{\prime}$-martensite transformation at large strains. In other words, for the CG core, the $\gamma \rightarrow \alpha^{\prime}$-martensitic deformation and the related TRIP effect occur only in the global strain range of $0.1-0.22$. This is consistent with what was observed in the uniform CG 304ss [38,39]. Fig. 9(b) shows the high initial $\alpha^{\prime}$-martensite content produced during SMAT processing in the gradient layer. Remarkably, a substantial rise of $\mathrm{V}_{\alpha^{\prime}}$ in the gradient layers starts at larger strains. For example, the $\gamma \rightarrow \alpha^{\prime}$-martensite transformation occurs in the global strain range of $0.22-0.38$ at the location of $160 \mu \mathrm{m}$ deep from the surface. In other words, the $\gamma \rightarrow \alpha^{\prime}$ martensite transformation in the gradient layers lagged behind the CG core.

Comparing Fig. 9(b) with Fig. 1(d) reveals that the $\gamma \rightarrow \alpha^{\prime}-$ martensite transformation occurred during the whole range of uniform deformation. In other words, the gradient structure enabled the $\gamma \rightarrow \alpha^{\prime}$-martensite transformation to last much longer than CG to help improving the ductility. In addition, the evolution of $\mathrm{V}_{\alpha^{\prime}}$ correlates well with the Hv changes in Fig. 2.

Fig. 9(b) also shows that $\mathrm{V}_{\alpha^{\prime}}$ in the free-standing $\mathrm{GL}_{5}^{0.04}$ film rises rapidly even at the low small strain. By the end of the uniform elongation, $V_{\alpha^{\prime}}$ at both sides is close to $97 \%$, which is larger than those at varying depths in the gradient layer. This is probably due to their much higher flow stresses.

\subsubsection{Microstructural evolution during tensile testing}

The parallelepiped domains shown in Figs. 5 and 6 is the basic microstructural unit for accommodating plastic deformation in the gradient layer. The plastic response determines the mechanical properties and strain hardening behavior of the gradient structured samples during tensile deformation. TEM observations were used to study the microstructural evolution in the parallelepiped domains with tensile strains in $\mathrm{GS}_{5}^{1}$ sample. The applied tensile strain for TEM studies was determined based on the $V_{\alpha^{\prime}}$ evolution in Fig. 9.

Fig. 10(a) shows the microstructure at $\sim 160 \mu \mathrm{m}$ deep at an applied tensile strain of 0.25 . A row of elongated domains was analyzed in detail. Several long plates (marked by red arrows) are determined to be $\alpha^{\prime}$-martensite according to SAED patterns. Each domain interior is still austenite. A large number of granular $\alpha^{\prime}$ martensite grains, indicated by blue triangles, are also seen, which are formed via $\varepsilon \rightarrow \alpha^{\prime}$ phase transformation. Both the volume fraction and grain sizes of $\alpha^{\prime}$-martensite are increased as compared to those shown in Figs. (5) and (6). Fig. 10(b) shows a domain taken at $\sim 120 \mu \mathrm{m}$ deep at an applied tensile strain of 0.3 . Four-side frames have been transformed completely to $\alpha^{\prime}$-martensite according to the SAED pattern. The $\alpha^{\prime}$-martensite deformed plastically and dislocation entanglement was formed in their interiors. The domain interior is still austenite but with dislocation cells. This type of microstructure should have the most differences in flow stresses between the domain frames and interior, as the frames have been transformed completely to $\alpha^{\prime}$-martensite. Therefore, local strain partitioning is strongest. As the applied tensile strain further increased to 0.35 at $\sim 50 \mu \mathrm{m}$ depth as seen in Fig. 10(c), all domain interiors were transformed into $\alpha^{\prime}$-martensite. The SAED pattern shows a discontinuous ring of the bcc structure. Dislocations are observed in $\alpha^{\prime}$-martensite. Fig. 10(d) shows a large number of granular and plate-shaped $\alpha^{\prime}$-martensite with a little $\varepsilon$-martensite left.

\section{Discussion}

\subsection{Dynamic strain partitioning}

The gradient structure reported here will cause strain partitioning during tensile tests. The strain partitioning has two origins at two different scales. One is macroscopic across the whole sample thickness, while the other is microscopic between the domain interior and walls of each parallelepiped domain. Both types of
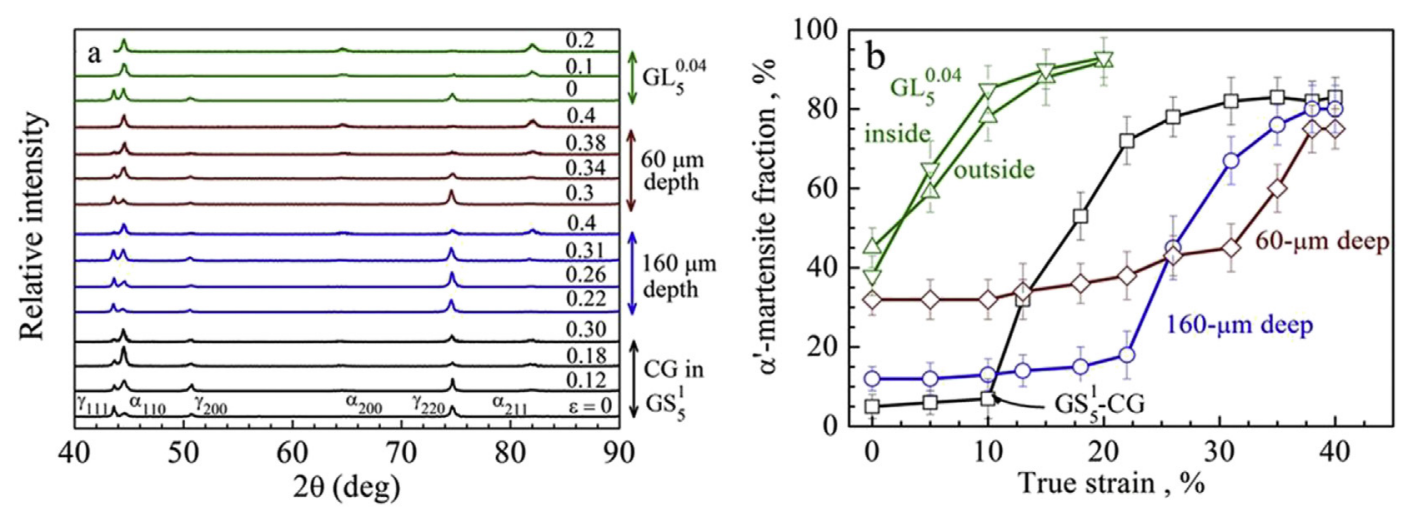

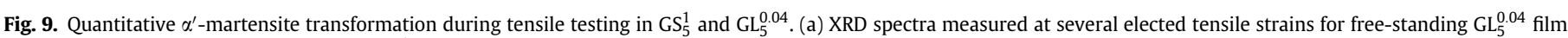

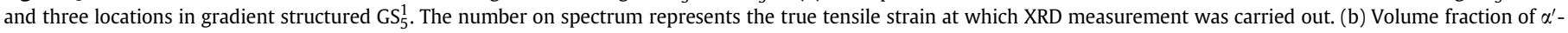
martensite as a function of tensile strains. 

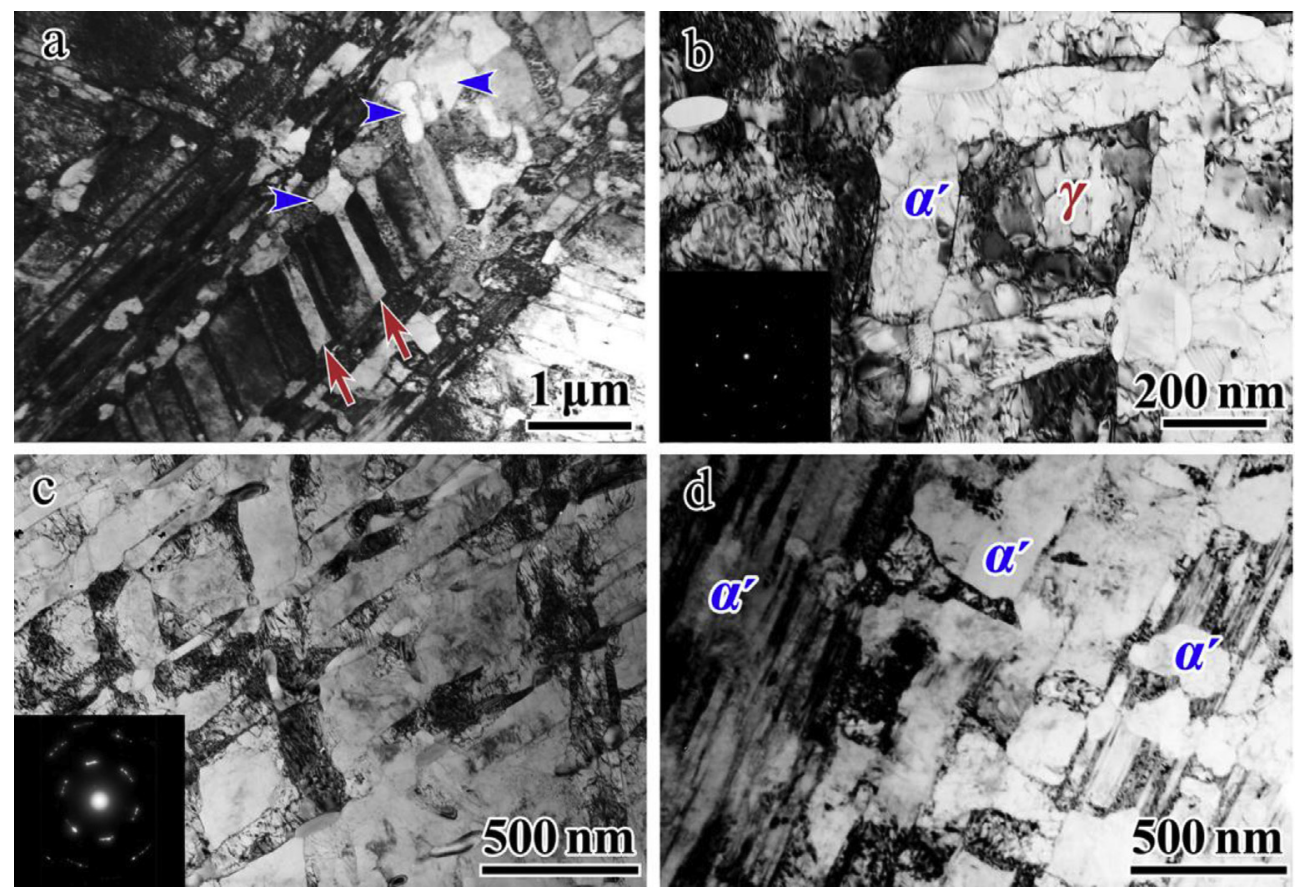

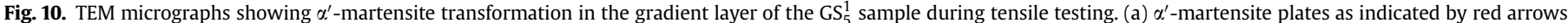

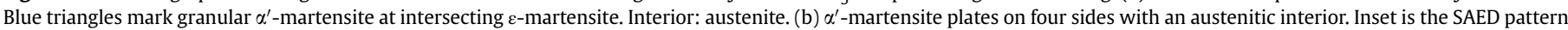

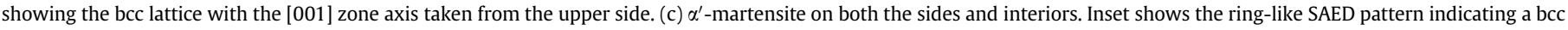
lattice. (d) $\alpha^{\prime}$-martensite. (For interpretation of the references to colour in this figure caption, the reader is referred to the web version of this article.)

strain partitioning evolve during tensile testing due to the dependence of the $\gamma \rightarrow \alpha^{\prime}$-martensite transformation with applied tensile strains and the austenite stability of domain sizes as well. In this sense, the dynamic strain partitioning is expected, similar to that in TRIP-maraging steel [12].

Macroscopically, a gradient $\mathrm{Hv}$ exists across the gradient structured sample as shown in Fig. 2. The Hv is lower in the CG core than that in gradient layers on both sides. The former yields first, while the latter is still deforming elastically. Hence, the gradient structure will begin with a composite-like deformation. As a result, the CG core bears more plastic deformation. This is evidenced by Hv evolutions with tensile strains as shown in Fig. 2. The Hv keeps nearly unchanged in most of the GL at tensile strains of 0.05 and 0.1 , respectively, in contrast to a gradual rise of $\mathrm{Hv}$ in the CG core due to strain hardening. This indicates the onset of strain partitioning between the central CG core and gradient layers. Furthermore, the whole gradient structured sample can be approximately regarded as the integration of many thin layers with increasing Hv toward the surface [34]. The plastic deformation occurs in sequence of neighboring layers with low to high flow stresses. As a result, plastic strain partitioning continues as the GL begins to deform plastically and lasts up to the end of the uniform elongation. The strain partitioning at the macroscale is, actually, an intrinsic property of the gradient structure due to the presence of the initial $\mathrm{Hv}$ gradient.

Microscopically, large Hv difference exists between the parallelepiped domains and martensitic domain walls. The austenite domains are softer than $\varepsilon$-martensite walls that surround domains from all sides as shown in Fig. 5. In addition, this Hv difference will be increased after the onset of the $\gamma \rightarrow \alpha^{\prime}$-martensite transformation in the domain walls upon further straining as seen in Fig. 10(a) and (b). The $\alpha^{\prime}$-martensite may deform plastically and store entangled dislocations. Besides, the $\gamma \rightarrow \alpha^{\prime}$-martensite transformation in the gradient layers begins at large strains and finishes by the end of uniform elongation based on the XRD measurements shown in Fig. 9(b). These observations suggest that the deformation is not uniform between the domain interiors and walls at the microscopic scale. In other words, dynamic strain partitioning occurs microscopically in each parallelepiped domain and continues until the final stage of uniform deformation. This microscopic strain partitioning can be mapped semi-in-situ using EBSD and image analysis [16].

The dynamic strain partitioning is associated with the mechanical incompatibility at both the macroscale and microscale. Firstly, two interfaces exist, demarcating the elastic and plastic layers in the gradient structure during tensile deformation. These interfaces will migrate toward the surface in the gradient layer with increasing applied strain as shown in Fig. 2. Mechanical incompatibility is produced at elastic/plastic interfaces. Secondly, mechanical incompatibility still exists between soft domains and their hard walls. As a result of these two types of mechanical incompatibility, strain gradients are generated near both elastic/ plastic interfaces [34] and austenite/martensite interfaces. These strain gradients produce geometrically necessary dislocations and increase both the yield strength and strain hardening [29,34,57]. It has been reported that mechanical incompatibility will also cause high back stress and back stress hardening [35,58]. Detailed investigations are being carried out to study this issue.

Both the soft CG layer and soft austenite domains will bear more strain than the hard ones during tensile deformation of the gradient structure. As a result, dynamic strain partitioning causes an enhanced uniform ductility, especially when strain partitioning lasts up to the end of uniform deformation.

\subsection{Deformation-induced phase transformation and TRIP effect}

The deformation-induced $\gamma \rightarrow \alpha^{\prime}$-martensite transformation plays a crucial role in strain hardening in homogeneous CG 304ss 
[38-43]. It induces a $\Theta$ rise as shown in Fig. 1(d). However, it is difficult for the phase transformation to last until the final strain stage. XRD measurements shown in Fig. 9(b) reveal the onset of the $\gamma \rightarrow \alpha^{\prime}$ transformation at first in the CG core in the gradient structured $\mathrm{GS}_{5}^{1}$. The $\mathrm{V}_{\alpha^{\prime}}$ rise in the CG core begins at true strain of $\sim 0.1$, slows down after the strain of 0.22 and finally stops at the strain of 0.3. In other words, the TRIP effect occurs only in the strain range from 0.1 to 0.3 for the CG core. It is noted that the strain of 0.1 happens to match that for the onset of $\Theta$ rise as shown in Fig. 1(d). This indicates that the $\gamma \rightarrow \alpha^{\prime}$ transformation in the CG core is responsible for $\Theta$ rise.

The starting strain for the onset of $\gamma \rightarrow \alpha^{\prime}$ transformation shifts to 0.1 in $\mathrm{GS}_{5}^{1}$, much smaller than 0.18 in homogeneous CG 304ss. This is likely caused by the complex evolution of the stress-state in the gradient structured sample. Plastically deforming metals should have an apparent Poisson's ratio of 0.5 , while elastic deformations usually have a Poisson's ratio of 0.3 [34,59]. As revealed in Fig. 2(a), the CG core has already started plastic deformation at the strain larger than $0.05 \%$, while gradient layers are still largely elastic. Under uniaxial tension, the CG core should laterally shrink more than elastic gradient layers. This will lead to tensile lateral stress in the CG layer and compressive lateral stress in the gradient layers. Since the $\gamma \rightarrow \alpha^{\prime}$ transformation is accompanied with volume expansion, the lateral tensile stress should promote the phase transformation [60,61], which is the reason why the onset of the $\gamma \rightarrow \alpha^{\prime}$ martensitic transformation for the CG layer is shifted to lower tensile strains in gradient structured samples.

Interestingly, a strong delay of the $\gamma \rightarrow \alpha^{\prime}$ transformation is visible in the gradient layers as seen in Fig. 9(b). This delay is caused mainly by three reasons. First, the austenite domains become smaller and smaller with decreasing distance to the surface. The small grain sizes deter the onset of phase transformation [11]. Second, the gradient layer only bears a lower plastic strain than the CG core due to the strain partitioning. Third, the lateral compressive stress in the gradient layer should also have played a significant role in delaying the martensitic transformation. It is further deduced from Figs. 1 and 9(b) that the $\gamma \rightarrow \alpha^{\prime}$ martensite transformation is controlled not only by the strain level and local stress state as discussed above, but also by the applied stress level. There exists probably a minimum stress level to trigger the phase transformation. The free-standing $\mathrm{GL}_{5}^{0.04}$ film starts the plastic deformation at very high stresses, which is why the $\gamma \rightarrow \alpha^{\prime}$-martensitic transformation may start almost immediately upon plastic deformation.

In the gradient structure the $\alpha^{\prime}$-martensite transformation takes place in the whole strain range from 0.1 to the sample failure, as seen in Fig. 9(b). In other words, the gradient structure enables the $\alpha^{\prime}$-martensite transformation, and consequently the TRIP effect, to last over a large strain rage, which effectively increases the uniform elongation. Taking the $\mathrm{GS}_{5}^{1}$ sample as an example, the $\alpha^{\prime}$-martensite transformation is prolonged to the strain of more than 0.3 , as compared to $\sim 0.25$ in the CG sample (see Fig. 9(b)).

The combination of the gradient structure and the TRIP effect produces a combination of strength and ductility that is superior to what was reported earlier, as shown in Fig. 11. This is especially true in the high strength regime, where the TRIP-gradient 304ss has much higher ductility than those reported for other homogeneous samples.

\section{Conclusions}

SMAT processing of 304 stainless steel has produced a gradient structure with two gradient structured layers sandwiching a coarse-grained core layer. The gradient layers consist of parallelepiped austenite domains separated by hard $\varepsilon$ martensite walls, and

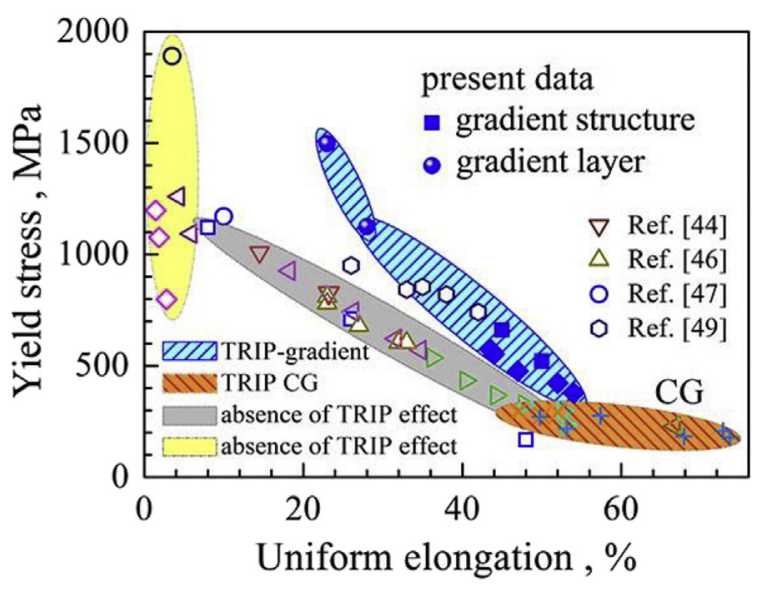

Fig. 11. Synergy of yield strength and uniform elongation produced by combination of gradient structure and TRIP effect in 304ss, as compared with those reported in 304ss with other types of microstructures.

a domain size gradient along the depth.

During tensile testing of the gradient structured 304ss samples, the CG core starts plastic deformation first, while the gradient layer is still deforming elastically, causing macroscopic strain partitioning and mechanical incompatibility, which consequently produces a tensile lateral stress in the CG core and compressive lateral stress in the gradient layers. The tensile lateral stress in the CG core promoted early $\gamma \rightarrow \alpha^{\prime}$-martensite transformation, while the compressive stress in the gradient layers delayed TRIP to a larger applied tensile strain. In addition, smaller domain size in the gradient layer also delays the $\alpha^{\prime}$-martensite transformation. As a result, the TRIP effect is prolonged to the end of the tensile test, in contrast to the TRIP effect in homogeneous CG samples, where TRIP effect usually ends early. In other words, the gradient structure can spread the TRIP effect over a larger strain range to enhance ductility.

The TRIP-gradient 304ss shows an excellent combination of yield strength and uniform elongation. The multiple plastic responses, including the dynamic strain partitioning and phase transformation intrinsically inter-linked with each other and cocontribute to the observed superior mechanical properties.

\section{Acknowledgements}

This work was financially supported by the National Natural Science Foundation of China (NSFC) under grant Nos. 11572328, 11222224, 11472286, the 973 Programs under grant Nos. 2012CB932203, 2012CB937500, and 6138504. Y.Z. was supported by the US Army Research Office (W911 NF-12-1-0009), the US National Science Foundation (DMT-1104667), and the Nanjing University of Science and Technology.

\section{References}

[1] R.Z. Valiev, Y. Estrin, Z. Horita, T.G. Langdon, M.J. Zehetbauer, Y.T. Zhu, Fundamentals of superior properties in bulk NanoSPD materials, Mater. Res. Lett. 4 (2016) 1-21.

[2] L. Lu, Y.F. Shen, X.H. Chen, L.H. Qian, K. Lu, Ultrahigh strength and high electrical conductivity in copper, Science 304 (2004) 422-426.

[3] X.L. Wu, P. Jiang, L. Chen, F.P. Yuan, Y.T. Zhu, Extraordinary strain hardening by gradient structure, Proc. Natl. Acad. Sci. U. S. A. 111 (2014) 7197-7201.

[4] Y.M. Wang, M.W. Chen, F.H. Zhou, E. Ma, High tensile ductility in a nanostructured metal, Nature 419 (2002) 912-915.

[5] X.X. Huang, N. Hansen, N. Tsuji, Hardening by annealing and softening by deformation in nanostructured metals, Science 312 (2006) 249-251.

[6] R.Z. Valiev, Nanostructuring of metals by severe plastic deformation for advanced properties, Nat. Mater. 3 (2004) 511-516. 
[7] Y.T. Zhu, X.Z. Liao, Nanostructured metals: retaining ductility, Nat. Mater. 3 (2004) 351-352.

[8] X.L. Wu, F.P. Yuan, M.X. Yang, C.X. Zhang, P. Jiang, L. Chen, Y.G. Wei, E. Ma, Nanodomained nickel unite nanocrystal strength with coarse-grain ductility, Sci. Rep. 5 (2015) 11728

[9] R.Z. Valiev, Y. Estrin, Z. Horita, T.G. Langdon, M.J. Zehetbauer, Y.T. Zhu, Producing bulk ultrafine-grained materials by severe plastic deformation: ten years later, JOM 68 (2016) 1216-1226.

[10] Y.M. Wang, E. Ma, Three strategies to achieve uniform tensile deformation in a nanostructured metal, Acta Mater. 52 (2004) 1699-1709.

[11] M.M. Wang, C.C. Tasan, D. Ponge, A. Kostka, D. Raabe, Smaller is less stable: size effects on twinning vs. transformation of reverted austenite in TRIPmaraging steels, Acta Mater. 79 (2014) 268-281.

[12] M.M. Wang, C.C. Tasan, D. Ponge, A.C. Dippel, D. Raabe, Nanolaminate transformation-induced plasticity-twinning-induced plasticity steel with dynamic strain partitioning and enhanced damage resistance, Acta Mater. 85 (2015) 216-228.

[13] M. Calcagnotto, Y. Adachi, D. Ponge, D. Raabe, Deformation and fracture mechanisms in fine- and ultrafine-grained ferrite/martensite dual-phase steels and the effect of aging. Acta Mater. 59 (2011) 658-670.

[14] D. Raabe, D. Ponge, O. Dmitrieva, B. Sander, Nanoprecipitate-hardened 1.5 GPa steels with unexpected high ductility, Scr. Mater. 60 (2009) 1141-1144.

[15] H.K.D.H. Bhadeshia, Nanostructured bainite, Proc. R. Soc. A 466 (2010) 3-18.

[16] J.H. Ryu, D.-I. Kim, H.S. Kim, H.K.D.H. Bhadeshia, D.-W. Suh, Strain partitioning and mechanical stability of retained austenite, Scr. Mater. 63 (2010) 297-299.

[17] C.C. Tasan, M. Diehl, D. Yan, C. Zambaldi, P. Shanthraj, F. Roters, D. Raabe, Integrated experimental-simulation analysis of stress and strain partitioning in multiphase alloys, Acta Mater. 81 (2014) 386-400.

[18] K. Sugimoto, M. Kobayashi, S. Hashimoto, Ductility, Strain-Induced, Transformation in a high-strength transformation-induced plasticity-aided dualphase steel, Metall. Mater. Trans. A 23 (1992) 3085-3091.

[19] C. Herrera, D. Ponge, D. Raabe, Design of a novel Mn-based 1 GPa duplex stainless TRIP steel with $60 \%$ ductility by a reduction of austenite stability, Acta Mater. 59 (2011) 4653-4664.

[20] H.L. Yi, K.Y. Lee, H.K.D.H. Bhadeshia, Extraordinary ductility in Al-bearing delta-TRIP steel, Proc. R. Soc. A 467 (2011) 234-243.

[21] S. Zaefferer, J. Ohlert, W. Bleck, A study of microstructure, transformation mechanisms and correlation between microstructure and mechanical properties of a low alloyed TRIP steel, Acta Mater. 52 (2004) 2765-2778.

[22] K.X. Tao, H. Choo, H.Q. Li, B. Clausen, J.E. Jin, Y.K. Lee, Transformation-induced plasticity in an ultrafine-grained steel: an in situ neutron diffraction study, Appl. Phys. Lett. 90 (2007) 101911.

[23] Y.S. Jung, Y.K. Lee, Effect of pre-deformation on the tensile properties of a metastable austenitic steel, Scr. Mater. 59 (2008) 47-50.

[24] L. Morales-Rivas, H.W. Yen, B.M. Huang, M. Kuntz, F.G. Caballero, J.R. Yang, C. Garcia-Mateo, Tensile response of two nanoscale bainite composite-like structures, JOM 67 (2015) 2223-2235.

[25] M.F. Ashby, Deformation of plastically non-homogeneous materials, Philos, Mag. 21 (1970) 399-411.

[26] H.J. Gao, Y.G. Huang, W.D. Nix, J.W. Hutchinson, Mechanism-based strain gradient plasticity - I. Theory, J. Mech. Phys. Solids 47 (1999) 1239-1263.

[27] H.J. Gao, Y.G. Huang, Geometrically necessary dislocation and size-dependent plasticity, Scr. Mater. 48 (2003) 113-118.

[28] T.H. Fang, W.L. Li, N.R. Tao, K. Lu, Revealing extraordinary intrinsic tensile plasticity in gradient nano-grained copper, Science 331 (2011) 1587-1590.

[29] X.L. Wu, M.X. Yang, F.P. Yuan, G.L. Wu, Y.J. Wei, X.X. Huang, Y.T. Zhu, Heterogeneous lamella structure unites ultrafine-grain strength with coarsegrain ductility, Proc. Natl. Acad. Sci. U. S. A. 112 (2015) 14501-14505.

[30] Y.J. Wei, Y.Q. Li, L.C. Zhu, Y. Liu, X.Q. Lei, G. Wang, Y.X. Wu, Z.L. Mi, J.B. Liu, H.T. Wang, H.J. Gao, Evading the strength- ductility trade-off dilemma in steel through gradient hierarchical nanotwins, Nat. Comm. 5 (2014) 3580.

[31] H.N. Kou, J. Lu, Y. Li, High-strength and high-ductility nanostructured and amorphous metallic materials, Adv. Mater. 26 (2014) 5518-5524.

[32] K. Lu, Making strong nanomaterials ductile with gradients, Science 345 (2014) $1455-1456$

[33] W.B. Li, F.P. Yuan, X.L. Wu, Atomistic tensile deformation mechanisms of Fe with gradient nano-grained structure, AIP Adv. 5 (2015) 087120.

[34] X.L. Wu, P. Jiang, L. Chen, J.F. Zhang, F.P. Yuan, Y.T. Zhu, Synergetic strengthening by gradient structure, Mater. Res. Lett. 2 (2014) 185-191.

[35] M.X. Yang, Y. Pan, F.P. Yuan, Y.T. Zhu, X.L. Wu, Back stress strengthening and strain hardening in gradient structure, Mater. Res. Lett. (2016), http:// dx.doi.org/10.1080/21663831.2016.1153004.

[36] G.L. Huang, D.K. Matlock, G. Krauss, Martensite formation, strain rate sensitivity, and deformation-behavior of type-304 stainless-steel sheet, Metall. Trans. A 20 (1989) 1239-1246.

[37] H.W. Zhang, Z.K. Hei, G. Liu, J. Lu, K. Lu, Formation of nanostructured surface layer on AISI 304 stainless steel by means of surface mechanical attrition treatment, Acta Mater. 51 (2003) 1871-1881.

[38] L.E. Murr, K.P. Staudhammer, S.S. Hecker, Effects of strain rate and strain rate on deformation- induced transformation in 304 stainless-steel: Part II Microstructure study, Metall. Trans. A 13 (1982) 627-635.

[39] A.K. De, J.G. Speer, D.K. Matlock, D.C. Murdock, M.C. Mataya, R.J. Comstock, Deformation-induced phase transformation and strain hardening in type 304 austenitic stainless steel, Metall. Mater. Trans. A 37A (2006) 1875-1886.

[40] Z.H. Cong, N. Jia, X. Sun, Y. Ren, J. Almer, Y.D. Wang, Stress and strain partitioning of ferrite and martensite during deformation, Metall. Mater. Trans. A 40A (2009) 1383-1387.

[41] H.C. Shin, T.K. Ta, Y.W. Chang, Kinetics of deformation induced martensitc transformation in a 304 strainless steel, Scr. Mater. 45 (2001) 823-829.

[42] S. Cheng, X.L. Wang, Z.L. Feng, B. Clausen, H. Choo, P.K. Liaw, Probing the characteristic deformation behaviors of transformation-induced plasticity steels, Metall. Mater. Trans. A 39A (2008) 3105-3112.

[43] J. Talonen, P. Nenonen, G. Pape, H. Hanninen, Effect of strain rate on the straininduced $\gamma \rightarrow \alpha^{\prime}$ - martensite transformation and mechanical properties of austenitic stainless steels, Metall. Mater. Trans. A 36A (2005) 421-432.

[44] X.S. Yang, S. Sun, X.L. Wu, E. Ma, T.Y. Zhang, Dissecting the mechanism of martensitic transformation via atomic-scale observations, Sci. Rep. 4 (2014) 6141.

[45] H.Y. Yi, F.K. Yan, N.R. Tao, K. Lu, Comparison of strength-ductility combinations between nanotwinned austenite and martensite-austenite stainless steels, Mater. Sci. Eng. A 647 (2015) 152-156.

[46] H.Y. Yi, F.K. Yan, N.R. Tao, K. Lu, Work hardening behavior of nanotwinned austenitic grains in a metastable austenitic stainless steel, Scr. Mater. 114 (2016) 133-136.

[47] C.X. Huang, W.P. Hu, Q.Y. Wang, C. Wabg, G. Yang, Y.T. Zhu, An ideal ultrafinegrained structure for high strength and high ductility, Mater. Res. Lett. 3 (2015) 88-94.

[48] Y.F. Shen, N. Jia, Y.D. Wang, X. Sun, L. Zuo, D. Raabe, Suppression of twinning and phase transformation in an ultrafine grained 2 GPa strong metastable austenitic steel: experiment and simulation, Acta Mater. 97 (2015) 305-315.

[49] A.Y. Chen, D.F. Li, J.B. Zhang, H.W. Song, J. Lu, Make nanostructured meta exceptionally tough by introducing non-localized fracture behaviors, Scr. Mater. 59 (2008) 579-582.

[50] A.Y. Chen, H.H. Ruan, J. Wang, H.L. Chan, Q. Wang, O. Li, J. Lu, The influence of strain rate on the microstructure transition of 304 stainless steel, Acta Mater. 59 (2011) 3697-3709.

[51] K. Lu, J. Lu, Nanostructured surface layer on metallic materials induced by surface mechanical attrition treatment, Mater. Sci. Eng. A 375 (2004) 38-45.

[52] X. Wu, N. Tao, Y. Hong, B. Xu, J. Lu, K. Lu, Microstructure and evolution of mechanically-induced ultrafine grain in surface layer of Al-alloy subjected to USSP, Acta Mater. 50 (2002) 2075-2084.

[53] J.L. Martin, B. Lo Piccolo, J. Bonneville, The role of thermal activation in the strength anomaly of $\mathrm{Ni}_{3} \mathrm{Al}$, Intermetallics 8 (2000) 1013-1018.

[54] A. Mishra, M. Martin, N.N. Thadhani, B.K. Kad, E.A. Kenik, M.A. Meyers, Highstrain-rate response of ultra-fine-grained copper, Acta Mater. 56 (2008) 2770-2783.

[55] F.P. Yuan, P. Jiang, X.L. Wu, Annealing effect on the evolution of adiabatic shear band under dynamic shear loading in ultra-fine-grained iron, Int. J. Imp. Eng. 50 (2012) 1-8

[56] F.P. Yuan, X.D. Bian, P. Jiang, M.X. Yang, X.L. Wu, Dynamic shear response and evolution mechanisms of adiabatic shear band in ultrafine-grained austeniteferrite duplex steel, Mech. Mater. 89 (2015) 47-58.

[57] J.J. Li, S.H. Chen, X.L. Wu, A.K. Soh, A physical model revealing strong strain hardening in nano-grained metals induced by grain size gradient structure Mater. Sci. Eng. A 620 (2014) 16-21.

[58] M.X. Yang, F.P. Yuan, Q.G. Xie, Y.D. Wang, E. Ma, X.L. Wu, Strain hardening in Fe-16Mn-10Al-0.86C-5Ni high specific strength steel, Acta Mater. 109 (2016) $213-222$

[59] C.W. Beat, E.J. Mills, W.S. Hyler, Effect of variation in poisson's ratio on plastic tensile instability, J. Fluids Eng. 89 (1967) 35-39.

[60] A.A. Lebedev, V.V. Kosarchuk, Influence of phase transformations on the mechanical properties of austenitic stainless steels, Int. J. Plast. 16 (2000) 749-767.

[61] P.J. Jacques, Q. Furnémont, F. Lani, T. Pardoen, F. Delannay, Multiscale mechanics of TRIP-assisted multiphase steels: I. Characterization and mechanical testing, Acta Mater. 55 (2007) 3681-3693. 